\title{
Theoretical Study of Two Possible Side Reactions for Reductive Functionalization of 3d Metal-Methyl Complexes by Hydroxide Ion: Deprotonation and Metal-Methyl Bond Dissociation
}

\author{
Hengameh Fallah ${ }^{1}$, Floyd Horng ${ }^{2}$, Thomas R. Cundari ${ }^{l *}$ \\ ${ }^{1}$ Department of Chemistry and Center for Advanced Scientific Computing and Modeling, University of North Texas, \\ 1155 Union Circle, \#305070, Denton, Texas 76203-5017, United States \\ ${ }^{2}$ Texas Academy of Mathematics and Science, University of North Texas, 1155 Union Circle, \#305309, Denton, \\ Texas 76203-5017, United States
}

\section{Supporting Data}

\begin{abstract}
Computational Methods
This research was performed using the Gaussian 09 software package. ${ }^{1}$ The B3LY ${ }^{2-5} / 6-31 \mathrm{G}(\mathrm{d})^{6-8}$ level of theory was employed based on published calibrations versus coupled clusters calculations for Co-methyl complexes by Piecuch et al. ${ }^{9}$ Calculations were done in DMSO solvent using the SMD continuum solvent model. ${ }^{10}$ All reasonable spin states (low, intermediate and high spin) for each $\mathrm{d}^{\mathrm{n}}$ electron configuration were evaluated for each metal and for all stationary points. The discussion in the paper focuses on those spin states determined to be the lowest on their respective free energy surfaces. All thermodynamic data were calculated assuming $\mathrm{T}=298.15 \mathrm{~K}$ and $\mathrm{P}=1$ bar. The vibrational frequencies were calculated to ascertain each stationary point as a minimum energy or transition state structure and unscaled frequencies utilized to make enthalpic and entropic corrections.
\end{abstract}

Table S-1. Relative free energies of possible spin states of deprotonation reaction of products. Type-a: $\left[\left(\mathrm{M}^{\mathrm{II}}(\text { diimine })_{2}\left(=\mathrm{CH}_{2}\right)(\mathrm{Cl})\right]^{-}+\mathrm{H}_{2} \mathrm{O}\right.$, Type-b: $\left[\left(\mathrm{M}^{\mathrm{II}}(\text { diimine })_{2}\left(=\mathrm{CH}_{2}\right)\left(\mathrm{OH}_{2}\right)\right]+\mathrm{Cl}^{-}\right.$, Type-c: $\left[\left(\mathrm{M}^{\mathrm{II}}(\text { diimine })_{2}\left(=\mathrm{CH}_{2}\right)\right]+\mathrm{H}_{2} \mathrm{O}+\mathrm{Cl}^{-}\right.$; $\mathrm{M}^{\mathrm{II}}=\mathrm{Ti}^{\mathrm{II}}$ through $\mathrm{Cu}^{\mathrm{II}}$. The spin states are described by a number after the type of product. For example, "Prod-a3" represents product type-a with triplet spin state.

* Products types a and b could not be found for the nickel(II) complex deprotonation product.

** Products types a and $\mathrm{b}$ could not be found for the copper(II) complex deprotonation product. As the only possible spin state for copper (II) is doublet, therefore "Prod-c2" (doublet-product type-c) is the most stable product for copper(II) complex deprotonation reaction.

\begin{tabular}{|c|c|c|}
\hline & & $\Delta \mathrm{G}(\mathrm{kcal} / \mathrm{mol})$ \\
\hline \multirow{5}{*}{$\operatorname{Ti}(\mathbf{I I})$} & Prod-a3 rel to Prod-a1 & 26.3 \\
\hline & Prod-b3 rel to Prod-b1 & 6.9 \\
\hline & Prod-c3 rel to Prod-c1 & 4.6 \\
\hline & Prod-a1 rel to (Prod-c1 + cl-) & -16.3 \\
\hline & Prod-b1 rel to (Prod-c1 + h2o) & 6.4 \\
\hline \multirow{5}{*}{ V(II) } & Prod-a4 rel to Prod-a2 & -1.5 \\
\hline & Prod-b4 rel to Prod-b2 & 8.0 \\
\hline & Prod-c4 rel to Prod-c2 & 5.4 \\
\hline & Prod-a4 rel to (Prod-c2 + cl-) & 20.0 \\
\hline & Prod-b2 rel to (Prod-c2 + h2o) & 10.3 \\
\hline \multirow{8}{*}{$\operatorname{Cr}(\mathrm{II})$} & Prod-a3 rel to Prod-a1 & -25.3 \\
\hline & Prod-a5 rel to Prod-a1 & -20.3 \\
\hline & Prod-b3 rel to Prod-b1 & -5.1 \\
\hline & Prod-b5 rel to Prod-b1 & -20.1 \\
\hline & Prod-c3 rel to Prod-c1 & -27.7 \\
\hline & Prod-c5 rel to Prod-c1 & -20.1 \\
\hline & Prod-a3 rel to (Prod-c3 + cl-) & 13.4 \\
\hline & Prod-b5 rel to (Prod-c3 + h2o) & 17.5 \\
\hline \multirow{3}{*}{$\operatorname{Mn}($ II) } & Prod-a4 rel to Prod-a2 & -13.2 \\
\hline & Prod-a6 rel to Prod-a2 & 17.6 \\
\hline & Prod-b4 rel to Prod-b2 & 4.6 \\
\hline
\end{tabular}




\begin{tabular}{|c|c|c|}
\hline & Prod-b6 rel to Prod-b2 & 33.2 \\
\hline & Prod-c4 rel to Prod-c2 & 5.6 \\
\hline & Prod-c6 rel to Prod-c2 & 11.6 \\
\hline & Prod-a4 rel to (Prod-c2 + cl-) & 8.0 \\
\hline & Prod-b2 rel to (Prod-c2 + h2o) & 5.5 \\
\hline \multirow{8}{*}{$\mathrm{Fe}(\mathrm{II})$} & Prod-a3 rel to Prod-a1 & 7.7 \\
\hline & Prod-a5 rel to Prod-a1 & 34.3 \\
\hline & Prod-b3 rel to Prod-b1 & 19.2 \\
\hline & Prod-b5 rel to Prod-b1 & 29.0 \\
\hline & Prod-c3 rel to Prod-c1 & 15.2 \\
\hline & Prod-c5 rel to Prod-c1 & 5.3 \\
\hline & Prod-a1 rel to (Prod-c1 + cl-) & 1.4 \\
\hline & Prod-b1 rel to (Prod-c1 + h2o) & 4.3 \\
\hline \multirow{5}{*}{$\mathrm{Co}(\mathrm{II})$} & Prod-a4 rel to Prod-a2 & 21.8 \\
\hline & Prod-b4 rel to Prod-b2 & 15.5 \\
\hline & Prod-c4 rel to Prod-c2 & 10.8 \\
\hline & Prod-a2 rel to (Prod-c2 + cl-) & 3.9 \\
\hline & Prod-b2 rel to (Prod-c2 + h2o) & 6.6 \\
\hline $\mathrm{Ni}(\mathrm{II})$ & Prod-c3 rel to Prod-c1 & 5.5 \\
\hline
\end{tabular}

Table S-2. Metal-methyl distance $(\AA)$ in other spin states of deprotonation transition states. The lowest energy spin states are shown in Bold.

\begin{tabular}{ccc}
\hline metal & M-CH3 Distance $(\AA)$ in R & M-CH3 Distance $(\AA)$ in TS \\
$\mathrm{V}^{\mathrm{II}}$ & $2.12(\mathrm{~d})$ & $2.01(\mathrm{~d})$ \\
& & $\mathbf{2 . 2 1}(\mathbf{q})$ \\
$\mathrm{Cr}^{\mathrm{II}}$ & $2.09(\mathrm{t})$ & $2.01(\mathrm{t})$ \\
& & $\mathbf{2 . 1 4}($ quin) \\
$\mathrm{Fe}^{\mathrm{II}}$ & $2.01(\mathrm{~s})$ & $1.91(\mathrm{~s})$ \\
& & $\mathbf{2 . 1 0}(\mathbf{q u i n})$ \\
$\mathrm{Co}^{\mathrm{II}}$ & $1.98(\mathrm{~d})$ & $\mathbf{1 . 9 2}(\mathbf{d})$ \\
$\mathrm{Ni}^{\mathrm{II}}$ & $1.93(\mathrm{~s})$ & $\mathbf{1 . 9 8}(\mathbf{s})$ \\
$\mathrm{Cu}^{\mathrm{II}}$ & $1.97(\mathrm{~d})$ & $\mathbf{1 . 9 7}(\mathbf{d})$ \\
\hline
\end{tabular}

The only complex that involves shrinking of the metal-methyl bond is $\mathrm{Co}^{\mathrm{II}}$-methyl complex, for which the reactants and deprotonation transition state are both low-spin (doublet), and which has a much lower activation free energy (-14.6 kcal/mol) than the other divalent metal ions studied. Metal-methyl bond distances in lower spin states of deprotonation transition states are given in Table S-2. It can be observed that except for Ni(II) complex, the metal-methyl bond distances involve shrinking from reactants to transition states if they are compared in same spin states. 
Figure S-1. Relative free energies of the lowest energy spin states of deprotonation reaction products type-a, type-b and type-c providing the structures.

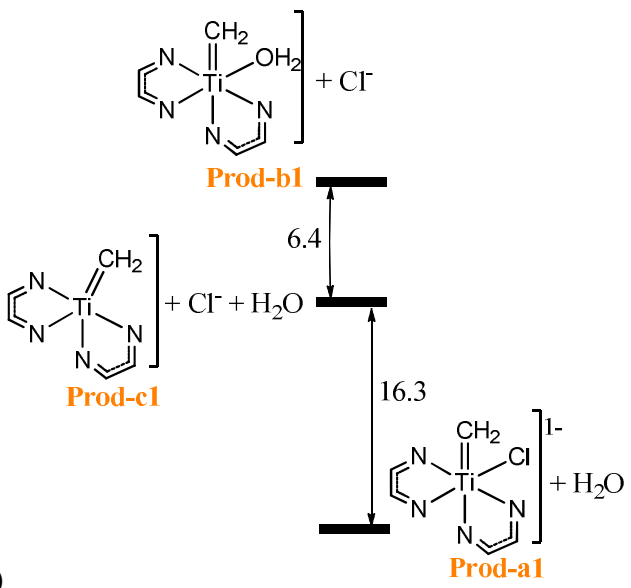

(b)
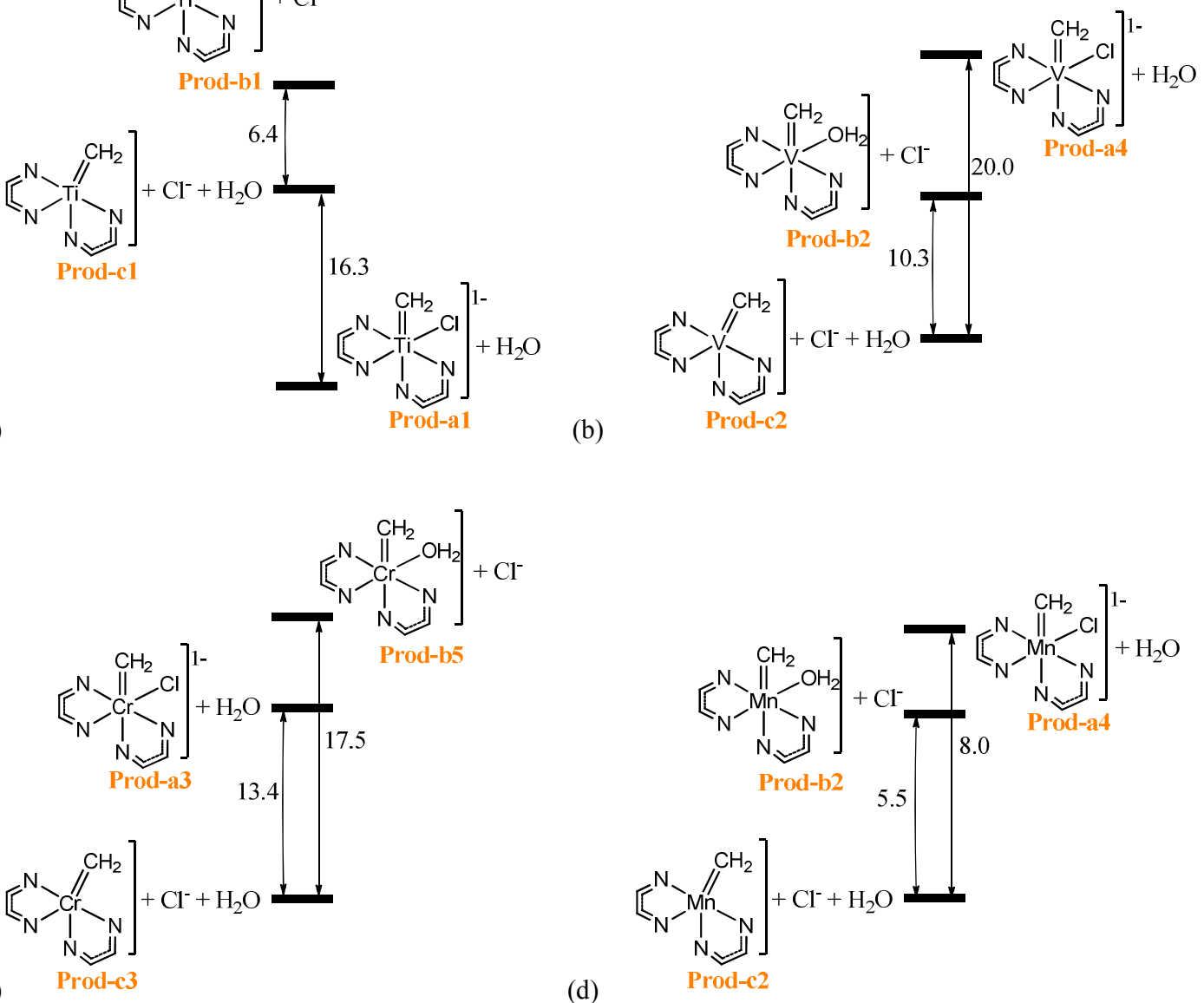

(d)
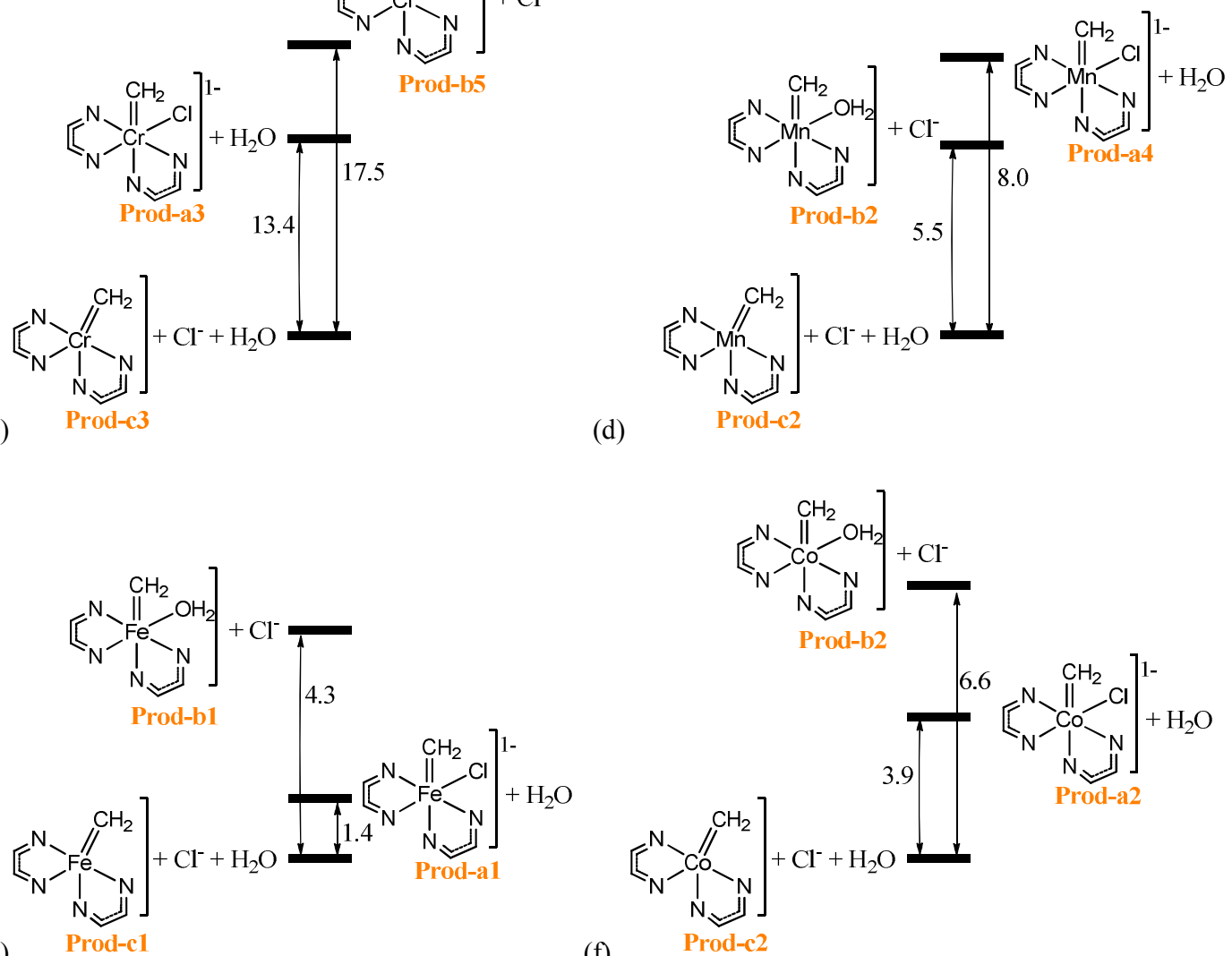

(e)

(f)

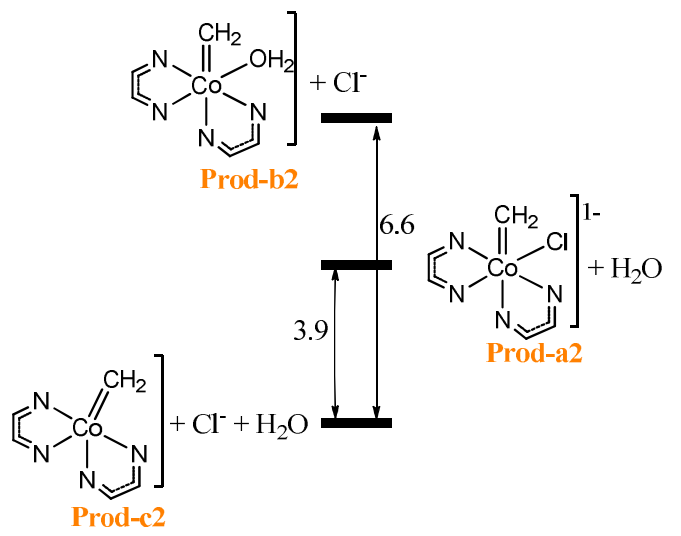

\section{References:}

[1] Frisch, M. J.; Trucks, G. W.; Schlegel, H. B.; Scuseria, G. E.; Robb, M. A.; Cheeseman, J. R.; Scalmani, G.; Barone, V.; Mennucci, B.; Petersson, G. A.; Nakatsuji, H.; Caricato, M.; Li, X.; Hratchian, H. P.; Izmaylov, A. F.; Bloino, J.; Zheng, G.; Sonnenberg, J. L.; Hada, M.; Ehara, M.; Toyota, K.; Fukuda, R.; Hasegawa, J.; Ishida, M.; Nakajima, T.; Honda, Y.; Kitao, O.; Nakai, H.; Vreven, T.; Montgomery, J. A., Jr.; Peralta, J. E.; Ogliaro, F.; Bearpark, M.; Heyd, J. J.; Brothers, E.; Kudin, K. N.; 
Staroverov, V. N.; Kobayashi, R.; Normand, J.; Raghavachari, K.; Rendell, A.; Burant, J. C.; Iyengar, S. S.; Tomasi, J.; Cossi, M.; Rega, N.; Millam, M. J.; Klene, M.; Knox, J. E.; Cross, J. B.; Bakken, V.; Adamo, C.; Jaramillo, J.; Gomperts, R.; Stratmann, R. E.; Yazyev, O.; Austin, A. J.; Cammi, R.; Pomelli, C.; Ochterski, J. W.; Martin, R. L.; Morokuma, K.; Zakrzewski, V. G.; Voth, G. A.; Salvador, P.; Dannenberg, J. J.; Dapprich, S.; Daniels, A. D.; Farkas, Ö.; Foresman, J. B.; Ortiz, J. V.; Cioslowski, J.; Fox, D. J. Gaussian 09, revision D.01, Gaussian Inc.: Wallingford CT, 2009.

[2] Becke, A. D. J. Chem. Phys. 1993, 98, 5648-5652.

[3] Lee, C.; Yang, W.; Parr, R. G. Phys. Rev. B 1988, 37, 785-789.

[4] Vosko, S.H.; Wilk, L; Nusair, M. Can. J. Phys. 1980, 58, 1200-1211.

[5] Stephens, P. J.; Devlin, F. J.; Chabalowski, C. F.; Frisch, M. J. J. Phys. Chem. 1994, 98, 11623-11627.

[6] Hariharan, P. C.; Pople, J. A. Theoret. Chimica Acta 1973, 28, 213-222.

[7] Francl, M. M.; Petro, W. J.; Hehre, W. J.; Binkley, J. S.; Gordon, M. S.; DeFrees, D. J.; Pople, J. A. J. Chem. Phys. 1982, 77, 3654-3665.

[8] Rassolov, V.; Pople, J. A.; Ratner, M.; Windus, T. L. J. Chem. Phys. 1998, 109, 1223-29.

[9] Kozlowski, P. M.; Kumar, M.; Piecuch, P.; Li, W.; Bauman, N. P.; Hansen, J. A.; Lodowski, P.; Jaworska, M. J. Chem. Theory Comput. 2012, 8, 1870-1894.

[10] Marenich, A. V.; Cramer, C. J.; Truhlar, D. G. J. Phys. Chem. B 2009, 113, 6378-96. 